\title{
Avaliação da Mineralização Apical em Dentes de CÃEs CoM Rizogênese Incompleta e Lesão Periapical Submetidos À IRRIGAÇÃo dos CANAIS RAdICULARES POR PRESSÃo APICAL NegATIVA
}

Tese de Doutorado apresentada à Faculdade de Odontologia de Ribeirão Preto da Universidade de São Paulo para a obtenção do título de Doutor em Ciências. Programa: Odontopediatria.

Área de Concentração: Odontopediatria.

Orientadora: Profa ${ }^{A}$. Dra ${ }^{A}$. Raquel Assed Bezerra Segato

Ribeirão Preto

2018 


\section{AutorizaÇÃo Para Reprodução}

Autorizo a reprodução e/ou divulgação total ou parcial da presente obra, por qualquer meio convencional ou eletrônico para fins de estudo e pesquisa, desde que citada a fonte.

MARCELA LOPES LINHARES

Ficha Catalográfica

Linhares, Marcela Lopes

Avaliação da mineralização apical em dentes de cães com rizogênese incompleta e lesão periapical submetidos à irrigação dos canais radiculares por pressão apical negativa. Ribeirão Preto, 2018.

79p.: il.; $30 \mathrm{~cm}$

Tese de Doutorado apresentada à Faculdade de Odontologia de Ribeirão Preto/USP - Área de concentração: Odontopediatria.

Orientadora: Profa. Dra. Raquel Assed Bezerra Segato

1. Lesão periapical; 2. Rizogênese incompleta; 3. Imunohistoquímica; 4. Endovac ${ }^{\circledR}$ 


\section{FOLHA DE APROVAÇÃo}

Linhares ML. Avaliação da mineralização apical angiogênese em dentes de cães com rizogênese incompleta e lesão periapical submetidos à irrigação dos canais radiculares por pressão apical negativa.

Tese de Doutorado apresentada à Faculdade de Odontologia de Ribeirão Preto da Universidade de São Paulo para a obtenção do título de Doutor em Ciências Programa: Odontopediatria.

Área de Concentração: Odontopediatria.

Data da defesa:

\section{BANCA EXAMINADORA}

$\operatorname{Prof}(a) \cdot \operatorname{Dr}(a) \cdot:$

Julgamento: Assinatura:

Prof(a).Dr(a).:

Julgamento: Assinatura:

$\operatorname{Prof}(a) \cdot \operatorname{Dr}(a) \cdot:$

Julgamento: Assinatura:

Orientador $\operatorname{Prof}(a) \cdot \operatorname{Dr}(a) .:$

Assinatura: 

Nascimento 04 de março de 1975 - Manaus/AM.

Filiação José Luberval Lemos Linhares

Thelma Maria Lopes Linhares.

2007-2011 Curso de Graduação.

Faculdade de Odontologia do Amazonas - IAES/AM.

2010-2012 Curso de Especialização em Endodontia.

Faculdade do Amazonas - IAES, Manaus, Brasil

Título: TÉCNICA DE OBTURAÇÃO TERMOPLÁSTICA COM SISTEMA OBTURA

II: RELATO DE CASO.

Orientador: Carlos Alberto Sales Júnior

2011-2018 Curso de Especialização em Prótese Dentária.

Faculdade do Amazonas - IAES, Manaus, Brasil

Título: REABILITAÇÃO ORAL IMPLANTO RETIDA EM PACIENTE PROGNATA EM

OVERDENTURE: RELATO DE CASO.

Orientador: Eudes Francisco da Silva Cunha 

$\mathcal{A}$ Deus...

Pela graça da vída.

Por me guiar pelos melhores caminhos.

Pela presença e conforto constantes.

Por me presentear com familiares e amigos maravilhosos.

Pela oportunidade de mais uma conquista!

Aos meus amados pais...

José Luberval Lemos Linhares e Thelma María Lopes Linhares

Por toda a confiança depositada em mim.

Pelo apoío e amor incondicionaís.

Por me proporcionarem condições para realizar meus sonhos. Por serem meus exemplos de vida e minha motivação!

Aos meus queridos tios e primo...

Zobélia María de Souza Lopes, Alberto Tadeu do Nascimento Borges e Luã Lopes Borges

Por todo apoio, amizade e incentivo.

Por acreditarem na minha capacidade

Por todos os momentos maravilhosos que compartilhamos no dia a dia!

Aos meus amados irmãos...

Márcio Lopes Linhares e Marcos Lopes Linhares.

Por todo apoio, amizade e incentivo.

Por acreditarem nos meus ideais.

Por todos os momentos maravilhosos que compartilhamos!

$\mathcal{A}$ minha amada companheira...

\section{María Kamíla Rocha Barreto}

Por estar presente nos momentos bons e nos dificeis.

Por toda a paciência que tem comigo.

Por todo apoio, amizade e incentivo.

Por todos os momentos maravilhosos que compartithamos.

$\mathcal{A}$ todos os meus familiares e amigos... Que sempre torceram por mim, e que também fazem parte dessa conquista! 
À minha orientadora Raquel Assed Bezerra da Segato

Por todos os ensinamentos, pela paciência e pela grande dedicação.

$\mathcal{A}$ senhora é minha fonte de inspiração e minha referência dentro da Odontología.

Um exemplo de excelência profissional e de amor à profissão.

Professora, eu tenho muito orulho de ser sua aluna.

Obrigada por todas as oportunidades, pela motivação constante

e por toda a confíança depositada em mim!

À Profa. Dra. Léa Assed Bezerra da Silva,

Por todas as oportunidades a mim oferecidas.

Pela grande contríbuição na minha formação acadêmica. Obrigada pelos ensinamentos e por toda a confiança!

À Carolina Maschietto Pucinellí, a minha mais profunda gratidão pela sua amizade e contribuição na minha formação, por compreender e aceitar minhas dificuldades em momentos difíceis para mim. Obrigada Carolzinha! Você é uma luz que continuará a brilhar e contribuir em prol de uma Odontologia de excelência.

À $\mathcal{N i l z a}$ Letícía Magalhães, pela grande simpatia, dedicação, apoio técnico e paciêncía! Obrigada pelos momentos de alegria e de cumplicidade! Você é especial! 
À Príscílla Coutinho Romualdo, por toda a ajuda nesse trabalho. Sempre tão carinhosa e sempre disposta a ajudar. Muito obrigada.

À Marília Pacífico Lucísano, a minha gratídão pela disponibilidade, atenção e paciêncía. Obrigada por todo o apoío. Você foi fundamental para o meu crescimento profissional e pessoal!

\section{Ao Prof. Dr. Prof. Paulo Nelson-Fífho,}

Muito obrigada por toda a ajuda, pelos ensinamentos transmitidos e pela disponibilidade.

Você é uma pessoa especial que transmite muita energía positiva, sempre me incentivando! 

$\dot{\mathcal{A}}$ Universidade de São Paulo, na pessoa do atual Reitor, Prof. Dr. Vahan Agopyan, e do Vice-Reitor, Prof. Dr. Antônio Carlos Hernandes.

À Faculdade de Odontología de Ribeirão Preto da Universidade de São Paulo, na pessoa do atual Diretora, Profa. Dra. Lea Assed Bezerra da Sílva, $e$ do Vice-Diretor, Prof. Dr. Arthur Belém Novaes Jr.

À Coordenação do Programa de Pós-Graduação em Odontopediatría da Faculdade de Odontología de Ríbeirão Preto da Universidade de São Paulo, na pessoa da Coordenadora, Profa. Dra. Raquel Assed Bezerra da Segato e da Vice-Coordenadora Profa. Dra. Lea Assed Bezerra.

Aos professores do Programa de Pós-Graduação da Faculdade de Odontología de Ribeirão Preto da Universidade de São Paulo: Prof. Dr. Alberto Consolaro, Profa. Dra. Aldevina Campos de Freitas, Profa. Dra. $\mathcal{A l e x a n d r a ~ M u s s o l i n o ~ d e ~ Q u e i r o z , ~ P r o f a . ~ D r a . ~ A n d i a r a ~ d e ~ R o s s i ~ D a l d e g a n , ~}$ Prof Fabricío Kítazono de Carvalho, Profa. Dra. Kranya Víctoría Díaz Serrano, Profa. Dra. Lea Assed Da Sílva, Profa. Dra. María Crístina Borsatto, Prof. Dr. Paulo Nelson Fílho, Profa. Dra. Raquel Assed Bezerra Da Sílva, Prof. Dr. Fábío Lourenço Romano, Prof. Dr. José Tarcísío Líma Ferreíra, Profa. Dra. Mirian Aiḱko Nakane Matsumoto, Profa. Dra. María Bernadete Sasso Stuani.

Aos Funcionários da Faculdade de Odontología de Ribeirão Preto: Carolina Paes Torres Mantovani, Fátíma, Aparecída Jacinto Daniel, Fílomena Leli Placcítí, Francísco Wanderlei García de Paula e Sílva, José Aparecido Neves do Nascímento, Karína Dadalt Quaglio, Marco Antônio dos Santos, Matheus Morelli Zanela, Micheli Cristina Leite Rovanholo, Nilza Letícia Magalhães, Tatiana Goudromîhos e Vera do Nascimento Scandelai. 
Aos Funcionários do Biotérío da Faculdade de Odontología de Ribeirão Preto da Universidade de São Paulo, Aldo Días Feíteíro Júníor, Raphael Martini Vícente e Edson Campos dos Santos.

Aos colegas da Pós-Graduação em Odontopediatría da Faculdade de Odontología de Ribeirão Preto da Universidade de São Paulo. 


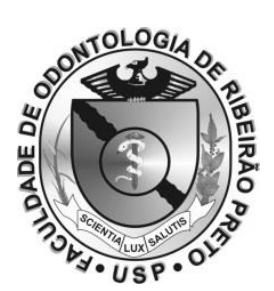

Trabalho desenvolvido nos Laboratórios de Histologia, Biologia Molecular e Cultura de Células do Departamento de Clínica Infantil da Faculdade de Odontologia de Ribeirão Preto Universidade de São Paulo, sob a orientação da Profa. Dra. Raquel Assed Bezerra Segato. 



\section{RESUMO}

Linhares, ML. Avaliação da mineralização em dentes com rizogênese incompleta e lesão periapical submetidos à irrigação dos canais radiculares por pressão apical negativa. Ribeirão Preto, 2018.

O objetivo desse estudo in vivo foi avaliar a intensidade de expressão de moléculas indicadoras da diferenciação celular com fenótipo mineralizador em dentes de cães com rizogênese incompleta e lesão periapical induzida experimentalmente submetidos à irrigação dos canais radiculares por pressão apical negativa $\left(E\right.$ ndoVac $\left.{ }^{\circledR}\right)$ e à irrigação por pressão apical positiva (irrigação convencional). Foram utilizados 30 dentes (60 raízes), divididos em 3 grupos: Grupo EndoVac ${ }^{\circledR}$ - Irrigação com pressão apical negativa $(n=20)$, Grupo Convencional - Irrigação com pressão apical positiva $(n=20)$; e Grupo Controle com Lesão Periapical $(n=20)$. Após indução de lesões periapicais, os canais radiculares dos grupos Endovac e Convencional foram instrumentados com limas manuais, empregando o sistema de irrigação correspondente. Decorridos 90 dias, os animais foram eutanasiados e os espécimes submetidos ao processamento histotécnico. Cortes representativos de cada grupo foram corados com hematoxilina e eosina (HE), para descrição histopatológica das regiões apical e periapical. Os cortes foram submetidos à para marcação de osteopontina (OPN), fosfatase alcalina (ALP) e fator de transcrição RUNX2 nas regiões apical e periapical das raízes. Para avaliação da intensidade da expressão desses marcadores foi realizada uma análise semi-quantitativa por meio de um sistema de escores. Os dados foram analisados estatisticamente pelo teste não-paramétrico de Kruskal-Wallis e pós-teste de Dunn e o nível de significância adotado foi de 5\%. Com relação à descrição histopatológica, achados distintos foram observados em cada grupo. Resumidamente, o grupo Endovac demonstrou um tecido conjuntivo bem organizado, invaginando-se para o interior do canal radicular, e exibiu um processo de reparo mais avançado, com relação aos demais grupos. A avaliação das imunomarcações para RUNX2 revelou que no grupo Endovac ${ }^{\circledR}$ houve marcação significantemente mais intensa $(p=0,03)$, em comparação ao grupo controle. Com relação à expressão de OPN, não foi possível encontrar diferença estatisticamente significante entre os grupos $(p=0,15)$. Após análise das imunomarcações para ALP, observou-se diferença estatisticamente significante entre os grupos $(p=0,0021)$, sendo que o grupo Endovac ${ }^{\circledR}$ apresentou marcação significantemente mais intensa com relação ao grupo controle. Os resultados do presente estudo in vivo permitiram concluir que a irrigação por pressão apical negativa (EndoVac $囚)$ apresentou potencial mineralizador, indicando ser o melhor sistema de irrigação para dentes com ápice incompleto e lesão periapical.

Palavras-chave: 1. Lesão periapical; 2. Rizogênese Incompleta; 3. Imunohistoquímica; 4. EndoVac ${ }^{\circledR}$ 



\section{ABSTRACT}

Linhares, ML. Evaluation of the mineralization in immature teeth with apical periodontitis subjected to negative apical pressure irrigation of root canals. Ribeirão Preto, 2018.

The objective of this in vivo study was to evaluate the expression intensity of molecules indicating cell differentiation with mineralizing phenotype in immature dogs teeth with experimentally induced apical periodontitis subjected to irrigation of root canals using negative apical pressure (EndoVac ${ }^{\circledR}$ ) and positive apical pressure (conventional irrigation). Thirty teeth (60 roots) were divided into 3 groups: EndoVac ${ }^{\circledR}$ Group - negative apical pressure irrigation ( $n=20)$, Conventional Group - positive apical pressure irrigation $(n=20)$; and Control Group with apical periodontitis $(n=20)$. After induction of periapical lesions, the root canals of the EndoVac ${ }^{\circledR}$ and Conventional groups were instrumented with hand files, using the corresponding irrigation system. After 90 days, the animals were euthanized and the specimens were submitted to histotechnical processing. Representative sections of each group were stained with hematoxylin and eosin ( $\mathrm{HE})$ for histopathological description of the apical and periapical regions. The sections were submitted to osteopontin (OPN), alkaline phosphatase (ALP) and RUNX2 transcription factor Immunostaining in the apical and periapical regions of the roots. A semi-quantitative analysis was performed to evaluate the expression intensity of these markers, using a score system. Data were statistically analyzed by the Kruskal-Wallis non-parametric test and Dunn post-test, and the significance level was set at $5 \%$. Regarding the histopathological description, different findings were observed in each group. Briefly, the EndoVac ${ }^{\circledR}$ group demonstrated a well-organized connective tissue, invaginating into the root canal, and exhibited a more advanced repair process in relation to the other groups. RUNX2 immunostaining revealed that in the EndoVac ${ }^{\circledR}$ group there was a significantly stronger $(p=0.03)$ immunostaining in comparison to the control group. Regarding the OPN expression, it was not possible to find a statistically significant difference between the groups $(p=0.15)$. After analyzing ALP immunostaining, a statistically significant difference was observed between the groups $(p=0.0021)$, and the EndoVac ${ }^{\circledR}$ group showed a markedly stronger mark immunostaining than the control group. The results of the present in vivo study allowed concluding that negative apical pressure irrigation (EndoVac ${ }^{\circledR}$ ) presented mineralizing potential, indicating that it is the best irrigation system for teeth with an open apex and apical periodontitis.

Key words: 1 . Apical periodontitis; 2. Immature teeth; 3. Immunohistochemistry; 4. EndoVac ${ }^{\circledR}$. 



\section{SUMÁRIO}

1. INTRODUÇÃO ................................................................................................ 21

2. PROPOSIÇÃO ............................................................................................ 29

3. MATERIAL E MÉTODOS ................................................................................ 33

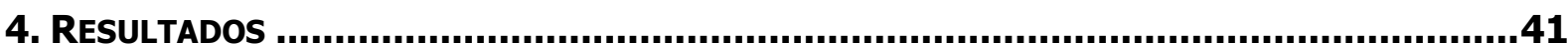

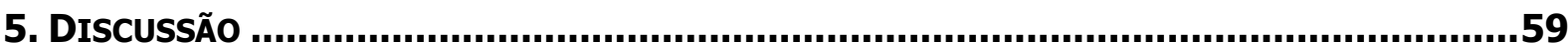

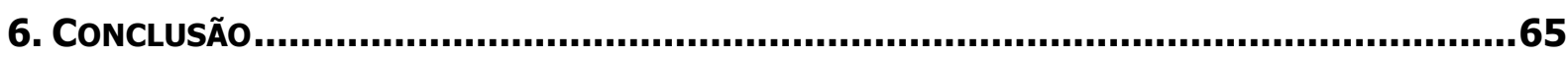

REFERÊNCIAS ..............................................................................................69

ANEXO.............................................................................................................. 77 



$$
\text { 1. Introdução }
$$





\section{INTRODUÇÃO}

Dentes com rizogênese incompleta são aqueles que ainda não atingiram o estágio 10 de Nolla e, portanto, não apresentam toda a camada de dentina radicular revestida por cemento. As raízes desses dentes apresentam paredes finas e frágeis e abertura apical acentuadamente ampla (Lin et al.,2017; da Silva, 2018). Quando ocorre necrose pulpar de um dente com rizogênese incompleta, a limpeza mecânica dos canais radiculares não é efetiva e não promove a conformação convencional para o travamento do cone de guta-percha principal, levando a um maior risco de insucesso no tratamento causado principalmente pela sobreobturação e selamento apical incompleto (Leonardo et al., 1993). Além disso, os dentes com rizogênese incompleta são mais amplos no sentido vestíbulo-lingual do que no mésio-distal, o que radiograficamente não permite avaliar com precisão a obturação radicular (Silva, 2005; 2018).

A terapia endodôntica bem-sucedida é baseada na remoção de todo o tecido pulpar, detritos dentinários, bactérias e suas endotoxinas do canal radicular (Schilder e Cleaning 1974). Metabólitos tóxicos e subprodutos liberados de micro-organismos presentes no sistema radicular difundem-se nos tecidos periapicais e provocam respostas inflamatórias acompanhadas de reabsorção óssea (Kakehashi et al.,1965). Perante o papel predominante dos micro-organismos na patologia pulpar e periapical, o tratamento endodôntico visa essencialmente a eliminação da infeç̧ão presente no sistema radicular. Conforme demonstrado por Sjøgren et al. 1997, o sucesso endodôntico está diretamente relacionado à presença ou ausência de microorganismos antes da obturação do canal radicular.

Sabe-se que quanto maior o diâmetro apical dos dentes, maior a tendência de extrusão inadvertida de solução irrigadora para os tecidos periapicais adjacentes (Mehra et al., 2000; Gernhardt et al., 2004; Aksel et al., 2014). Ainda hoje, a técnica de irrigação convencional é a mais utilizada pelos cirurgiões-dentistas ao redor do mundo (Dutner et al., 2012; Willershausen et al., 2015). Para esta técnica utilizase, basicamente, uma seringa para introduzir a solução irrigadora no interior dos canais radiculares até seu comprimento real de trabalho. Paralelamente, esta solução é aspirada por uma ponta de sucção acoplada ao sugador de alta potência 
do equipo odontológico. Na literatura específica esta técnica é conhecida como irrigação por pressão apical positiva.

Sabe-se que mesmo em dentes com ápice completo, o emprego dessa técnica de irrigação por pressão apical positiva promove a extrusão inadvertida de solução irrigadora para os tecidos periapicais (Druttman e Stock, 1989), devido à proximidade do bisel da agulha ao ápice radicular, podendo resultar em danos aos tecidos adjacentes (Hülsmann e Hahn, 2000; Desai e Himel, 2009; Mitchell et al., 2010), dor pós-operatória (Gondim Jr et al., 2010), desconforto, inchaço (Zhu et al., 2013). Além disso, na presença de necrose pulpar, esses danos podem ser mais severos devido à possível extrusão de debris contaminados à região periapical.

Em 2007, nos Estados Unidos surgiu no comércio odontológico especializado um sistema de irrigação por pressão apical negativa chamado EndoVac ${ }^{\circledR}$ (Discus Dental, Culver City, CA, EUA). Esse sistema utiliza duas fases: a macroirrigação e a microirrigação. A ponta que promove a irrigação / aspiração é inserida em uma seringa de irrigação descartável, adaptada à sucção de alta potência do equipo odontológico. A ponta de irrigação/aspiração libera a solução irrigadora na câmara pulpar e o excesso pode ser removido tanto pela macro quanto pela microcânula. A macrocânula é plástica e apresenta uma abertura final medida de acordo com os padrões da International Organization for Standardization (ISO) no calibre de 55 (ou $0,55 \mathrm{~mm}$ ) com taper 0,2 . Já a microcânula, de aço inoxidável e com uma extremidade fechada, apresenta doze pequenos orifícios posicionados lateralmente e calibre de acordo com os padrões ISO de 32 (ou $0,32 \mathrm{~mm}$ ) e esta deve ser inserida até o comprimento de trabalho. Dentre as vantagens do emprego desse sistema de irrigação dos canais radiculares por pressão apical negativa destaca-se uma reduzida extrusão de irrigante além do forame apical (Romualdo et al., 2017; Azim et al., 2018; Venumbaka et al., 2018), inclusive em dentes com rizogênese completa (Fukumoto et al.,2006; Velmurugan et al., 2014), ou até a não extrusão de solução irrigadora para a região periapical, durante sua utilização (Desai et al., 2009). Sabe-se também que a remoção da smear layer é significativamente mais eficaz quando utiliza-se o EndoVac ${ }^{\circledR}$, em comparação à irrigação convencional e a outros sistemas de irrigação, principalmente no terço apical do canal radicular (Fukumoto et al., 
2006; Karade et al., 2017; Buldur e Kapdan, 2017; Suman et al., 2017; Mancini et al., 2018).

A literatura é consistente ao demonstrar que a irrigação por pressão negativa tem melhor capacidade de remoção de debris, principalmente no terço apical, quando comparado à irrigação convencional (Nielsen e Baumgartner, 2007; Shin et al., 2010; Abarajithan et al., 2011; Gade et al., 2013; Alkahtani et al., 2014; Dua e Dua, 2015; Versiani et al., 2016; Karade et al., 2017; Suman et al., 2017). Ainda, observou-se um desempenho mais eficaz na limpeza (Karade et al., 2017), não só da luz do canal principal, mas também dos canais colaterais, quando esse sistema foi utilizado (Tanomaru-Filho et al., 2015), apresentando também capacidade antimicrobiana (Cohenca et al., 2010; de Miranda et al., 2015; Zeng et al., 2018).

Paralelamente, o Endovac promove melhor distribuição da solução irrigadora por todo o comprimento de trabalho (Adorno et al., 2015) e o seu emprego permite uma maior penetrabilidade do material obturador na dentina tubular, principalmente no terço apical do canal (Kara Tuncer e Unal, 2014; Machado et al., 2018). Assim, o preparo biomecânico associado ao sistema de irrigação por pressão negativa pode ser considerado um protocolo terapêutico promissor para o combate à infecção do sistema de canais radiculares de dentes com lesão periapical (Hockett et al., 2008; da Silva et al., 2010; Cohenca et al., 2013), inclusive nos casos de rizogênese incompleta (Cohenca et al., 2010; Rodríguez-Benítez et al., 2014).

Em dentes infectados e com lesão periapical crônica, as bactérias podem persistir nas ramificações do canal radicular principal, nos túbulos dentinários expostos, nas lacunas do cemento celular e no forame apical, ou seja, fora da luz do canal radicular principal (Rocha et al., 2008; Wang et al., 2012), que são áreas inacessíveis ao preparo biomecânico. Deste modo, a medicação intracanal utilizada no tratamento endodôntico preconizada por vários autores para dentes decíduos e permanentes portadores de lesão periapical inclui a realização de um curativo de demora, geralmente à base de hidróxido de cálcio (Rafter, 2005; da Silva et al., 2010; Vera et al., 2012; AAPD, 2016; Lin et al., 2017; Silva, 2018).

Durante o preparo biomecânico algumas áreas desse sistema de canais radiculares não são atingidas (Vaudt et al., 2009), sendo que pelo menos 35\% das paredes radiculares permanecem intactas (Peters et al., 2001). Esses dados 
enfatizam a importância de se associar um sistema de irrigação efetivo para potencializar a capacidade de limpeza dessa etapa do tratamento endodôntico (Byström e Sundqvist, 1981; Saber e Hashem, 2011). Em dentes com rizogênese incompleta, o maior diâmetro do canal e a divergência apical das paredes dificultam a eliminação da infecção, sendo a região apical desses dentes considerada uma área crítica devido ao grande acúmulo de micro-organismos e de material necrótico, principalmente na presença de lesão periapical.

De acordo com da Silva et al. (2010), o emprego do Endovac promoveu uma adequada limpeza e desinfecção do sistema de canais radiculares, sem ocasionar irritação aos tecidos periapicais, criando condições favoráveis para a ocorrência do processo de reparo. Segundo os autores, nos dentes tratados por esse sistema, foi possível observar um tecido conjuntivo periodontal mais organizado, com discreto infiltrado inflamatório, e a formação de tecido mineralizado em nível apical, comparado ao grupo tratado por meio de irrigação convencional e medicação intracanal com pasta triantibiótica.

Recentemente, o potencial indutor de reparo tecidual proporcionado pelo Endovac foi comprovado por Pucinelli et al.(2017). Embora a medida da extensão do ligamento periodontal não tenha sido estatisticamente diferente entre os grupos, os espécimes submetidos à irrigação por pressão negativa apresentaram número de osteoclastos ao redor da lesão significativamente menor, em comparação ao emprego da irrigação convencional. Ressalta-se que este estudo, assim como o anterior, foi conduzido em dentes de cães com desenvolvimento radicular incompleto e lesão periapical.

Da Silva et al. (2010) e Pucinelli et al. (2017) evidenciaram que a ampla abertura apical era preenchida por uma matriz de tecido conjuntivo denso bem estruturado, rica em fibroblastos jovens e vasos sanguíneos neoformados, que invaginava-se para o interior do canal radicular. Esse tecido de origem periodontal, em muitos casos, encontrava-se em diferentes estágios de mineralização, exibindo morfologias variadas. Sabendo da importância da técnica de imunomarcação para o entendimento de processos fisiológicos e patológicos, a identificação de marcadores responsáveis pela osteogênese pode elucidar os mecanismos envolvidos na formação desse tecido. 
Pelo exposto, considerando que:

a) dentes com rizogênese incompleta apresentam características anatômicas peculiares que dificultam a realização de diversas etapas do tratamento endodôntico, como a eliminação da infecção, risco de extrusão de solução irrigadora e de material necrótico à região periapical e possibilidade de sobreobturação e selamento apical incompleto;

b) o emprego do sistema de irrigação por pressão negativa é mais eficaz para a remoção de debris e de smear layer, principalmente do terço apical, previne a extrusão de solução irrigadora à região periapical e apresenta melhor capacidade de limpeza do sistema de canais radiculares;

c) procedimentos de revascularização têm sido propostos para o tratamento de dentes com necrose pulpar e desenvolvimento radicular incompleto;

d) e que estudos demonstraram que a utilização do Endovac estimula intensa invaginação de tecido conjuntivo com diferentes graus de mineralização para o interior do canal;

O objetivo da pesquisa é avaliar os processos de mineralização em dentes de cães com rizogênese incompleta e lesão periapical induzida experimentalmente submetidos à irrigação dos canais radiculares por pressão apical negativa $\left(\right.$ EndoVac $\left.^{\circledR}\right)$ e à irrigação por pressão apical positiva (irrigação convencional). 

2. Proposição 



\section{ProposiçÃo}

O presente estudo in vivo tem como objetivo avaliar a intensidade de expressão de moléculas indicadoras da diferenciação celular com fenótipo mineralizador em dentes de cães com rizogênese incompleta e lesão periapical induzida experimentalmente submetidos à irrigação dos canais radiculares por pressão apical negativa $\left(\operatorname{EndoVac}^{\circledR}\right)$ e à irrigação por pressão apical positiva (irrigação convencional). 

3. Material e Métodos 



\section{Material e Métodos}

Inicialmente o projeto de pesquisa foi submetido à apreciação pelo Comitê de Ética no Ensino e Pesquisa em Animais da Faculdade de Odontologia de Bauru, tendo sido aprovado (Processo $n^{\circ}$ 006/2012). $O$ estudo teve como base os protocolos recomendados pela International Organizacional Standardization (ISO 7405:2008) e por trabalhos previamente publicados (da Silva et al., 2012; Cohenca et al., 2015).

\section{Animais}

Foram utilizados 3 cães da raça Beagle, com 4 meses de idade. Para que estivessem em condições adequadas para o experimento, os animais foram mantidos em quarentena e receberam vermífugos, suplementos vitamínicos e vacinas antirrábica e tríplice. Durante todo o período experimental, os cães ficaram alojados no Biotério da Faculdade de Odontologia de Ribeirão Preto - Universidade de São Paulo (FORP/USP), com livre acesso à água e ração padrão. Foram selecionados os segundos e terceiros pré-molares superiores e segundos, terceiros e quartos prémolares inferiores, com rizogênese incompleta, totalizando 30 dentes (60 raízes), os quais foram divididos em 3 grupos (Tabela 1).

Tabela 1. Distribuição dos grupos

\begin{tabular}{|c|c|}
\hline & Procedimentos Procedimentos \\
\hline Grupo EndoVac ${ }^{\circledR}$ & $\begin{array}{l}\text { Irrigação por pressão apical negativa (EndoVac }{ }^{\circledR} \text { ) } \\
\text { (Grupo experimental: } 10 \text { dentes; } 20 \text { raízes) }\end{array}$ \\
\hline Grupo Convencional & $\begin{array}{l}\text { Irrigação convencional por pressão apical positiva } \\
\text { (Grupo Experimental: } 10 \text { dentes; } 20 \text { raízes) }\end{array}$ \\
\hline $\begin{array}{l}\text { Grupo com Lesão } \\
\text { Periapical }\end{array}$ & $\begin{array}{c}\text { Dentes com lesão periapical induzida, sem tratamento endodôntico } \\
\text { (Grupo experimental: } 10 \text { dentes; } 20 \text { raízes) }\end{array}$ \\
\hline
\end{tabular}

\section{Indução das Lesões Periapicais}

Previamente ao início dos estudos, os dentes selecionados foram examinados radiograficamente para confirmação da presença de rizogênese incompleta. Os animais foram pré - anestesiados por meio de injeção endovenosa de Neozine (Farmácia Aventis Ltda., São Paulo, SP, Brasil; $1 \mathrm{mg} / \mathrm{Kg}$ de peso corpóreo), 15 minutos antes do procedimento operatório quando, então, foram anestesiados com injeção endovenosa de cloridrato de tiletamina/cloridrato de zolazepam (Zoletil 50; Virbac do Brasil Ind. e Com Ltda., São Paulo, SP, Brasil; 0,1mL/kg de peso corpóreo) para facilitar a passagem do tubo endotraqueal. A anestesia inalatória com isoflurano 
(Abbott Laboratories Ltd., St. Laurent, Quebec, Canadá) foi efetuada usando o aparelho Takaoka KT-20 (Takaoka Indústria e Comércio Ltda, São Paulo, SP, Brasil). Durante todo o procedimento operatório, os animais foram mantidos com solução salina isotônica ( $\mathrm{NaCl}$ a 0,9\%-Glicolabor Indústria Farmacêutica Ltda., Ribeirão Preto, SP, Brasil). Todo esse procedimento de anestesia e acompanhamento do animal foi realizado por um médico-veterinário experiente.

A abertura coronária foi realizada com pontas esféricas e cônicas diamantadas (KG Sorensen, São Paulo, SP, Brasil), sob refrigeração abundante. 0 tecido pulpar coronário e radicular foi removido e os canais radiculares permaneceram expostos na cavidade bucal durante 7 dias, conforme preconizado em trabalhos prévios (Leonardo et al., 1993), para possibilitar a contaminação microbiana. Após esse período, a câmara pulpar foi selada com cimento de óxido de zinco e eugenol (S.S. White, Rio de Janeiro, RJ, Brasil), a fim de promover a indução das lesões periapicais.

Foram realizadas radiografias padronizadas, em intervalos de 5 dias, até que fosse observada uma rarefação óssea periapical indicativa de desenvolvimento da lesão periapical, que ocorreu em um período entre 15 e 25 dias (Leonardo et al., 1993).

\section{Neutralização do Conteúdo Necrótico}

Os dentes dos grupos EndoVac ${ }^{\circledR}$ e Convencional foram isolados com dique de borracha e o campo operatório submetido à antissepsia com digluconato de clorexidina a $2 \%$. Após secagem, o selamento temporário de óxido de zinco e eugenol foi removido e foi realizada a neutralização do conteúdo necrótico no sentido coroa-ápice, sob constante irrigação com hipoclorito de sódio ( $\mathrm{NaOCl}$ ) a 2,5\%, com um volume de no mínimo $3,6 \mathrm{~mL}$ de solução a cada troca de instrumento, até o Comprimento de Trabalho Provisório, situado a aproximadamente $3 \mathrm{~mm}$ do ápice radiográfico. Em seguida, foi efetuada a odontometria, para determinação do Comprimento Real de Trabalho (CRT), estabelecido a $1 \mathrm{~mm}$ aquém do ápice radicular, seguida de complementação da neutralização do conteúdo séptico-tóxico até esse limite.

\section{Instrumentação e Irrigação dos Canais Radiculares}


Grupo EndoVac ${ }^{\circledR}$ - Irrigação com pressão apical negativa (Sistema EndoVac ${ }^{\circledR}$ )

Os canais radiculares foram instrumentados no CRT, usando limas tipo K, até o calibre 70. Neste grupo, a irrigação por pressão apical negativa (sistema EndoVac ${ }^{\circledR} ;$ Discus Dental) foi empregada durante a instrumentação. Embora o protocolo recomendado para o uso deste sistema envolva 2 fases (macroirrigação e microirrigação), neste trabalho os canais radiculares foram irrigados apenas com a macrocânula, como preconizado por da Silva et al. (2010), devido ao tamanho apical aumentado de dentes com rizogênese incompleta.

Durante a macroirrigação, $10 \mathrm{~mL}$ de solução de $\mathrm{NaOCl}$ a $2,5 \%$ foram utilizados empregando a ponta de irrigação principal na abertura coronária. A macrocânula foi, então, retirada do canal radicular, mantendo-o totalmente preenchido com a solução irrigadora.

Todos os canais radiculares receberam irrigação final com solução salina esterilizada e foram secos com pontas de papel absorvente esterilizadas. Por fim, os dentes foram restaurados com selamento duplo, por meio do uso de ProRoot MTA (Dentsply Tulsa Dental, Johnson City, TN) e amálgama de prata (Sybraloy; Kerr Corporation, Orange, CA).

Grupo Convencional - Irrigação com pressão apical positiva (Irrigação convencional)

Neste grupo, os canais radiculares foram instrumentados no CRT, com limas tipo K, até o calibre 70, empregando-se virrigação com pressão apical positiva (irrigação convencional). A irrigação foi efetuada usando agulha esterilizada de calibre 30 (Max-i-Probe; Dentisply/Tulsa Dental, York, PA) conectada a uma seringa, preenchida com $10 \mathrm{~mL}$ de $\mathrm{NaOCl}$ a 2,5\%. A agulha foi introduzida no canal radicular até o CRT, sempre acompanhada pela cânula de aspiração, sob leve pressão. Todos os canais radiculares receberam irrigação final com solução salina esterilizada e foram secos com pontas de papel absorventes esterilizadas. Os dentes foram restaurados com selamento duplo, como descrito para o Grupo EndoVac ${ }^{\circledR}$. 
Grupo de dentes com lesão periapical sem tratamento endodôntico

Neste grupo, não foi realizado tratamento endodôntico. Após a indução das lesões, os dentes foram selados com MTA e amálgama de prata, como realizado nos Grupos EndoVac ${ }^{\circledR}$ e Convencional.

Durante todo o experimento e período pós-operatório, os cães foram monitorados diariamente, contando com o auxílio de um médico veterinário.

\section{Processamento Histotécnico}

Decorridos 90 dias, os animais foram eutanasiados por sobredose endovenosa de pentobarbital sódico. As maxilas e mandíbulas contendo os dentes foram dissecadas e seccionadas para se obter raízes individuais, as quais foram fixadas em formalina tamponada a $10 \%$ por 48 horas à temperatura ambiente e, em seguida, lavadas por aproximadamente 8 horas em água corrente. Para a descalcificação das peças, foi utilizada uma solução à base de EDTA a $20 \%(\mathrm{pH} 7,4)$. As peças foram mantidas nesta solução, à temperatura ambiente sob constante agitação. A solução desmineralizadora foi trocada semanalmente até a completa descalcificação das amostras, avaliada por meio da penetração de uma agulha nos tecidos para verificação da sua consistência. Decorridos aproximadamente 30 dias, as peças desmineralizadas foram neutralizadas em solução de sulfato de sódio a $5 \%$ (Sulfato de Sódio Anhidro; J.T.Baker, Xalostoc, México) por 24 horas, lavadas em água corrente por 12 horas, desidratadas em concentrações crescentes de álcool (Álcool Etílico Absoluto Anhidro; J. T. Baker), diafanizadas em xilol ( Xilol; Merck) e incluídas em parafina (Histosec Pastillen; Merck). Os blocos contendo os dentes foram cortados longitunalmente em micrótomo (Leica RM2145; Leica Microsystems $\mathrm{GmbH}$, Wetzlar, Alemanha) no sentido mésio-distal. Cortes semi-seriados de $5 \mu \mathrm{m}$, com intervalos de $15 \mu \mathrm{m}$, foram obtidos em toda a extensão da lesão periapical, exceto na região do forame apical, onde todos os cortes foram coletados sem intervalos.

Cortes representativos foram corados com hematoxilina e eosina (HE), para descrição das características das regiões apical e periapical, evidenciando os principais achados histopatológicos de cada grupo. 


\section{Imunohistoquímica}

Após obtenção das lâminas contendo os cortes, foram realizadas as reações de imunohistoquímica por meio da técnica da imunoperoxidase para marcação de moléculas relacionadas à mineralização e à neoformação óssea, como o fator de transcrição relacionado ao runt ( RUNX-2), a osteopontina (OPN) e a fosfatase alcalina (ALP).

Os cortes histológicos foram desparafinizados, sendo os epítopos antigênicos recuperados com calor utilizando tampão citrato $(\mathrm{pH}=6,0)$ no microondas (duas vezes de 10 segundos). Após retornarem à temperatura ambiente, as lâminas foram lavadas 2 vezes por 10 minutos com PBS e 1 vez com solução PBS/Triton a 0,5\% (Sigma-Aldrich Corporation, Saint Louis, EUA), pelo mesmo período. O bloqueio da peroxidase endógena foi realizado com peróxido de hidrogênio a 3\%, por 20 minutos. Posteriormente, as lâminas foram novamente lavadas com PBS e PBS/Triton conforme descrito anteriormente.

O bloqueio das ligações inespecíficas foi realizado com solução de $1 \%$ BSA (albumina de soro bovino)/PBS, por 30 minutos. Em seguida, as lâminas foram incubadas overnight em geladeira com os anticorpos primários diluídos em BSA 1\%: RUNX-2 (ab23981 policlonal produzido em coelhos, Abcam, Cambridge, MA, EUA), osteopontina (ab8448, policlonal produzido em coelhos, Abcam, Cambridge, MA, EUA) e fosfatase alcalina (ab54778, monoclonal produzido em camundongos, Abcam, Cambridge, MA, EUA). Após retornarem à temperatura ambiente, as lâminas foram lavadas da mesmo maneira descrita anteriormente e incubadas com anticorpo secundário anti-camundongo (sc 2039, Santa Cruz Biotechnology, Inc, Dallas, Texas, USA ) ou anti-coelho biotinilado (sc2040, Santa Cruz Biotechnology, Inc, Dallas, Texas, USA) diluídos 1:200, por 1 hora à temperatura ambiente. Depois de nova lavagem, foi colocado o complexo avidina-biotina-peroxidase ( $A B C$ kit, Vecstain; Vector Laboratories Inc.) por 30 minutos. A seguir, as lâminas foram novamente lavadas com PBS e PBS/Triton e a revelação da reação foi efetuada com solução de diaminobenzidina (DAB; Sigma-Aldrich Corporation, Saint Louis, EUA) e $\mathrm{H}_{2} \mathrm{O}_{2}$ a $3 \%$ em PBS por 1 minuto. As lâminas foram contra-coradas com Hematoxilina de Harris por 10 segundos, lavadas em água corrente, em água amoniacal por 30 segundos, e 
novamente em água corrente, sendo, em seguida, diafanizadas, desidratadas e montadas.

A análise foi realizada em microscópio Axio Imager.M1 (Carl Zeiss MicroImaging GmbH, Göttingen, Alemanha), acoplado a uma câmera Axiocam MRc5, por um examinador experiente, calibrado e cego para os grupos, sob luz convencional. Os resultados das marcações positivas para RUNX-2, OPN e ALP foram avaliados nas regiões apical e periapical, e a intensidade da expressão desses marcadores foi classificada de acordo com os seguintes escores: (0) ausente; (1) suave; (2) moderado; ou (3) intenso. Os dados foram transformados em porcentagem e os grupos comparados entre si.

\section{Análise Estatística}

Os dados obtidos foram submetidos à análise estatística apropriada, por meio do programa Graph Pad Prism 6.0 (Graph Pad Software Inc, San Diego, CA, EUA). Para a comparação dos resultados obtidos, nos diferentes grupos, foi aplicado o teste não-paramétrico de Kruskal-Wallis e, quando necessário, o pós - teste de Dunn. Todas as análises foram realizadas com nível de significância de $5 \%$. 
4. Resultados 



\section{Resultados}

\section{Análise Histopatológica}

Os principais achados histopatológicos de cada grupo estão ilustrados na Figura 1. No grupo Controle (lesão sem tratamento), observou-se lesões periapicais extensas, apresentando um tecido pobremente organizado, com reduzida população celular, dissociação fibrilar e reabsorção dos tecidos mineralizados, com presença de osteoclastos nas lacunas de Howship (Figura 1 A, B e C). O grupo tratado pela irrigação convencional exibiu um tecido conjuntivo mais organizado, com presença de células inflamatórias, predominantemente mononucleadas, fibras colágenas neoformadas e alguns vasos sanguíneos. A superfície óssea apresentava áreas ligeiramente irregulares. Estes eventos indicam estágio inicial de reparação da lesão periapical, porém não induziu o selamento biológico apical (Figura 1 D, E e F). Com relação aos espécimes submetidos à irrigação por pressão negativa, foi observada a presença de um tecido conjuntivo exibindo graus variados de mineralização, o qual invaginava-se no interior do canal, permitindo a ocorrência de um processo semelhante à revascularização. Este grupo demonstrou um tecido bem organizado, rico em fibroblastos jovens, fibras colágenas, vasos sanguíneos, presença de algumas células infamatórias mononucleadas, difusas pelo tecido, e osteoblastos recobrindo a superfície óssea. Estas características indicam que o Endovac induziu o processo de reparo da lesão periapical (Figura 1 G, H e I). 
Figura 1. Fotomicrografias ilustrando os principais achados histopatológicos de cada grupo. (A) Visão panorâmica do espécime do grupo Controle exibindo extensa lesão periapical e um tecido conjuntivo pobremente organizado, com reduzida população celular, como evidenciado em maior aumento na imagem (C). (B) Maior aumento da imagem A, evidenciando superfície óssea irregular, com presença de osteoclastos. (D) Visão panorâmica do espécime do grupo Convencional, demonstrando estágio inicial de reparação da lesão periapical, porém sem invaginar-se para o interior do canal radicular. (E) Detalhe da superfície óssea em reparação com presença de fibras colágenas e alguns ostoeblastos, porém com algumas áreas irregulares. $(F)$ Detalhe do tecido conjuntivo evidenciando células inflamatórias predominantemente mononucleadas, alguns vasos sanguíneos e fibras colágenas. (G) Visão panorâmica do espécime do grupo Endovac, exibindo um tecido conjuntivo bem organizado, invaginando-se para o interior do canal radicular, rico em vasos sanguíneos. (H) Detalhe da superfície óssea, que se mostra regular, com presença de osteoblastos. Nota-se presença de densos feixes de fibras colágenas e um infiltrado inflamatório suave e mononuclear, difuso pelo tecido. (I) Maior aumento do tecido conjuntivo presente no interior do canal radicular, exibindo grande quantidade de fibroblastos jovens e fibras colágenas, vasos sanguíneos e nódulos mineralizados. Figuras $A, D$ e $G=$ aumento de 50X; Figuras B, E e H = aumento de 200X; C, F e I = aumento de 400X. 

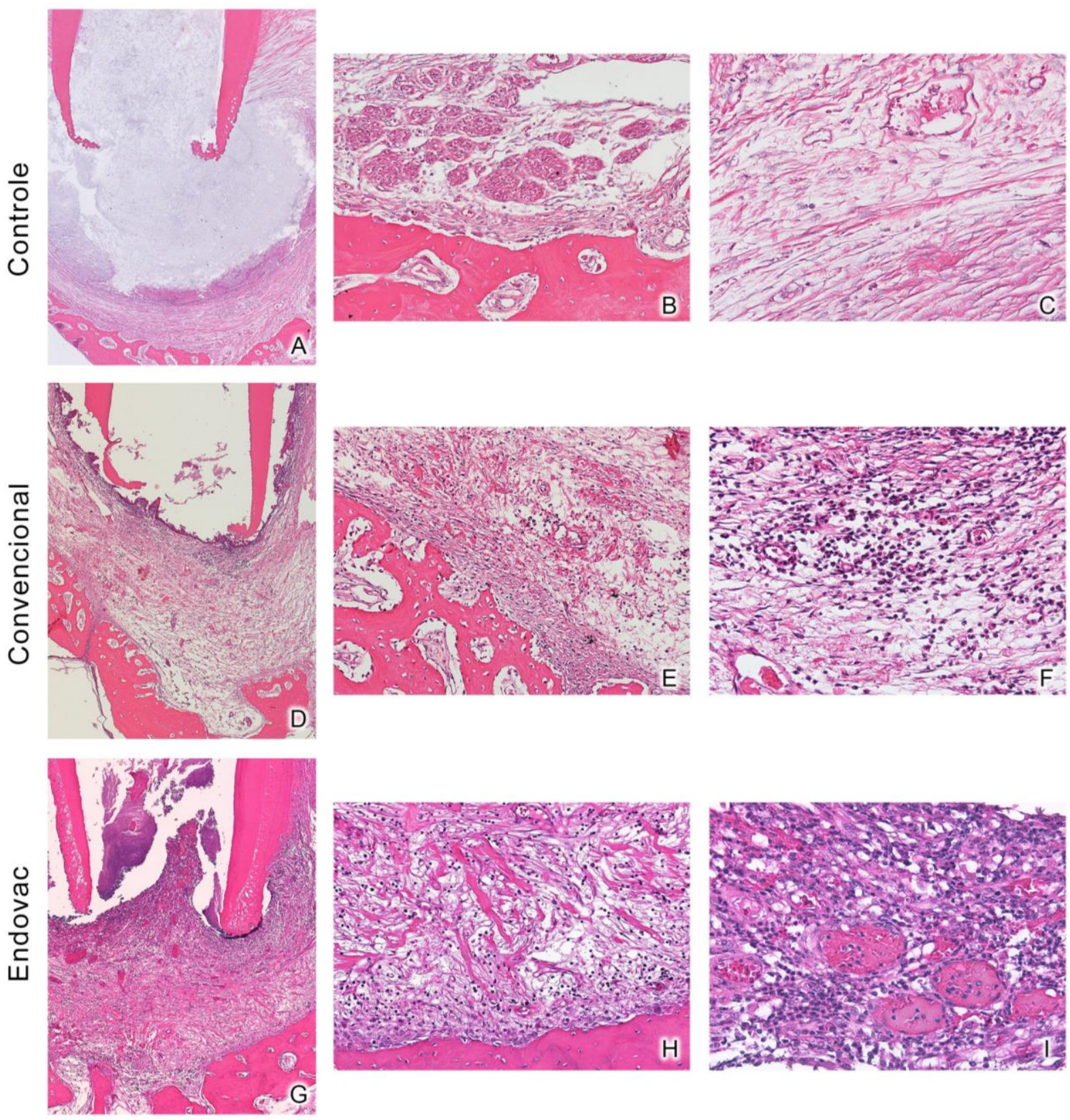



\section{Imunohistoquímica}

A análise estatística após a avaliação das imunomarcações para RUNX2 (Figura 2) revelou que no grupo Endovac houve marcação significantemente mais intensa $(p=0,03)$, em comparação ao grupo controle. Em porcentagem e considerando a intensidade da marcação positiva para RUNX2 como suave, moderada e intensa, foram obtidos os seguintes resultados, respectivamente: $75 \%$, $25 \%$ e $0 \%$ para o grupo controle; $25 \%, 62,5 \%$ e $12,5 \%$ para a irrigação convencional; e $25 \%, 25 \%$ e $50 \%$ para o Endovac. A Figura 3 ilustra a imunomarcação para o fator de transcrição relacionado ao runt (RUNX-2) representativa de cada grupo.

Figura 2. Escores obtidos após a avaliação das imunomarcações para RUNX2 e comparação entre os grupos. Escore 1 = imunomarcação suave; $2=$ moderada; 3 = intensa. Letras diferentes indicam diferença estatisticamente significante $(p=0,03)$

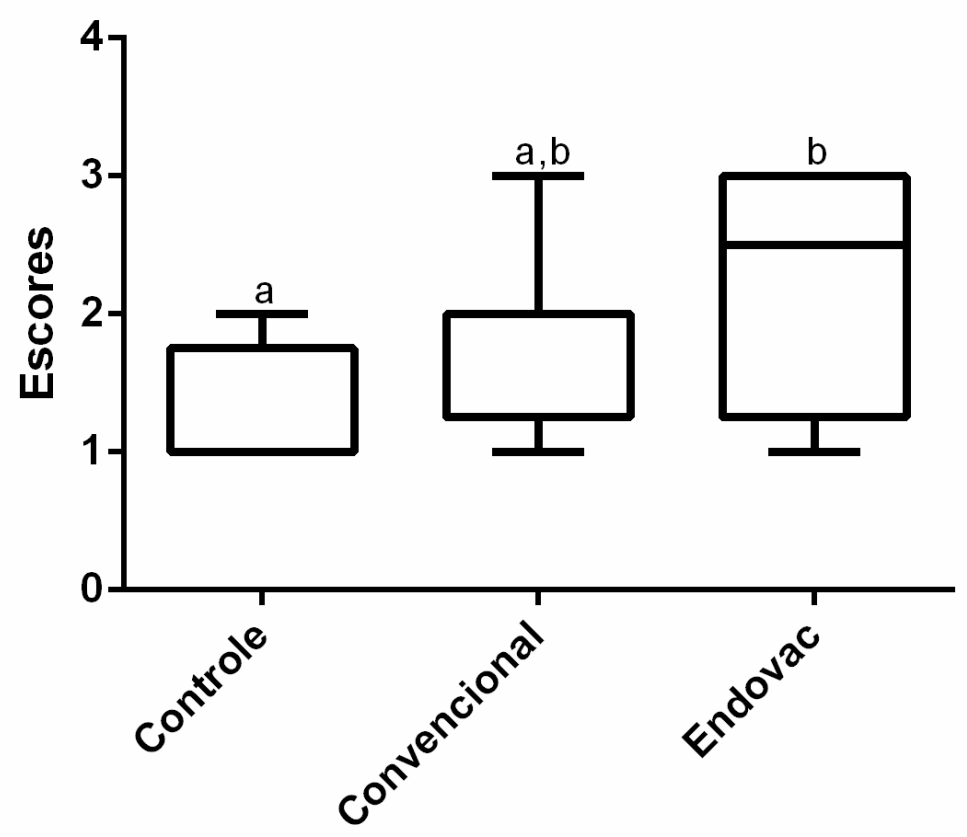


Figura 3. Fotomicrografias representativas da intensidade de imunomarcação para o fator de transcrição relacionado ao runt (RUNX-2) nos diferentes grupos. (A) Visão panorâmica do espécime do grupo Controle demonstrando marcação muito discreta para RUNX2. (B) Maior aumento da Figura A, evidenciando marcação suave de RUNX2 nas lacunas cementárias. (C) Visão panorâmica do espécime do grupo Convencional demonstrando marcação moderada para RUNX2, evidenciada em maior aumento na imagem (D), onde observa-se essa marcação concentrada próximo ao osso alveolar. (E) Visão panorâmica do espécime do grupo Endovac demonstrando marcação mais intensa em toda raiz, inclusive no tecido formado no interior do canal radicular. A imagem (F) demonstra em maior aumento a marcação intensa de RUNX2 na região do ligamento periodontal. Figuras $A, C$ e $E=$ aumento de 50X; Figuras B, D e F = aumento de 200X. 

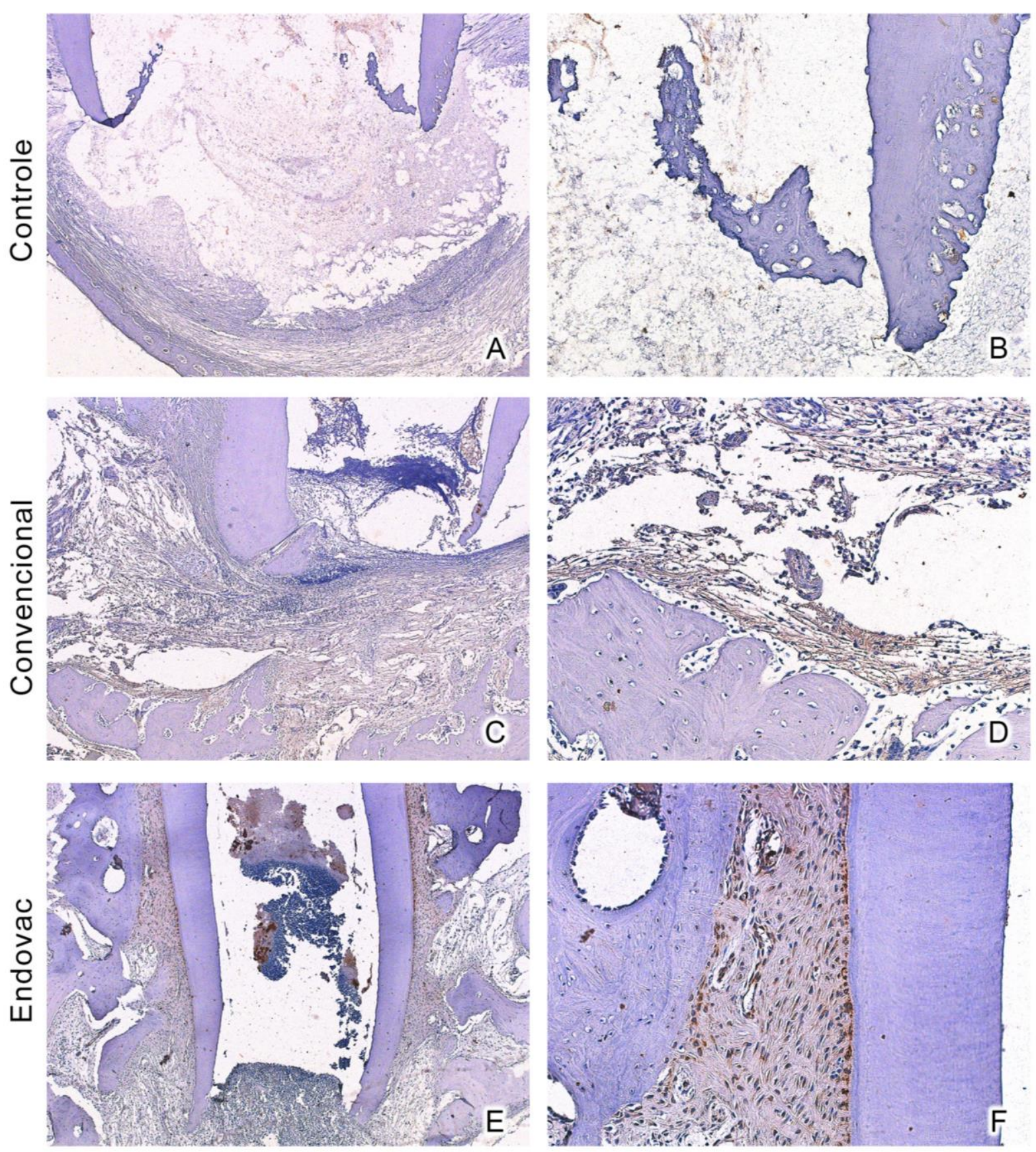

Com relação à avaliação das imunomarcações para OPN (Figura 4), não foi possível encontrar diferença estatisticamente significante entre os grupos $(p=0,15)$. Em porcentagem e considerando a intensidade da marcação positiva para OPN como suave, moderada e intensa, foram obtidos os seguintes resultados, respectivamente: $50 \%, 37,5 \%$ e $12,5 \%$ para o grupo controle; $12,5 \%, 62,5 \%$ e $25 \%$ para a irrigação convencional; e 50\%, 50\% e $0 \%$ para o Endovac. A Figura 5 ilustra a intensidade de imunomarcação para a Osteopontina (OPN) representativa de cada grupo.

Figura 4. Escores obtidos após a avaliação das imunomarcações para OPN e comparação entre os grupos. Escore $1=$ imunomarcação suave; $2=$ moderada; 3 = intensa. Letras iguais indicam que não houve diferença estatisticamente significante $(p=0,15)$

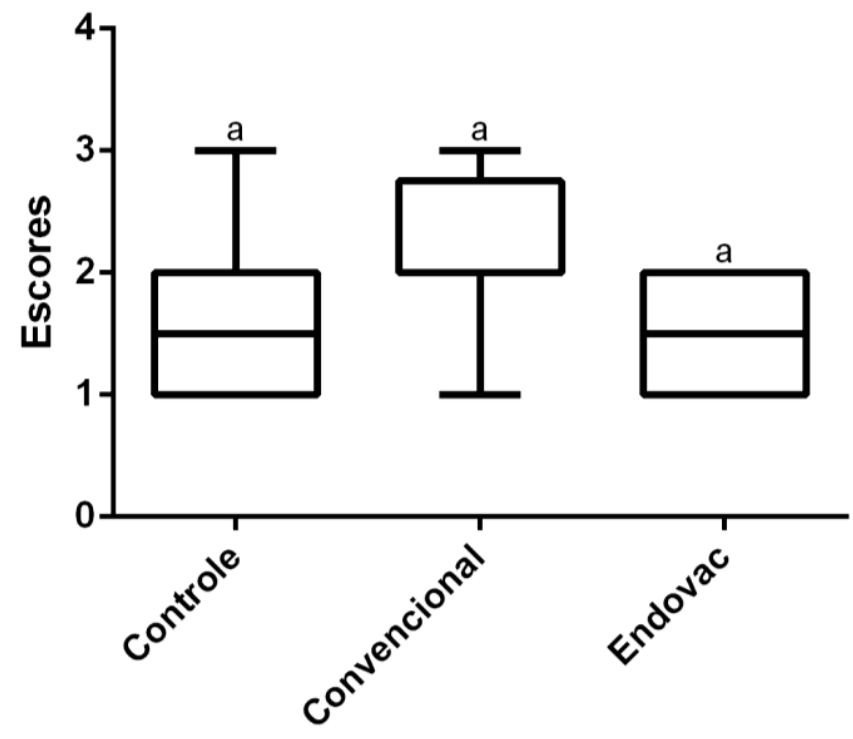


Figura 5. Fotomicrografias representativas da intensidade de imunomarcação para a Osteopontina (OPN) nos diferentes grupos. (A) Visão panorâmica do espécime do grupo Controle evidenciando marcação suave para OPN. (B) Maior aumento da Figura A, evidenciando marcação suave de OPN na lesão periapical próximo ao cemento apical. (C) Visão panorâmica do espécime do grupo Convencional demonstrando marcação moderada para OPN. (D) Detalhe da imagem anterior, evidenciando marcação moderada na lesão periapical próximo ao cemento apical. (E) Visão panorâmica do espécime do grupo Endovac demonstrando marcação moderada de OPN, concentrada nas lacunas cementárias, como evidenciando em maior aumento na imagem ( $F)$. Figuras $A, C$ e $E=$ aumento de 50X; Figuras B, D e F = aumento de 200X. 

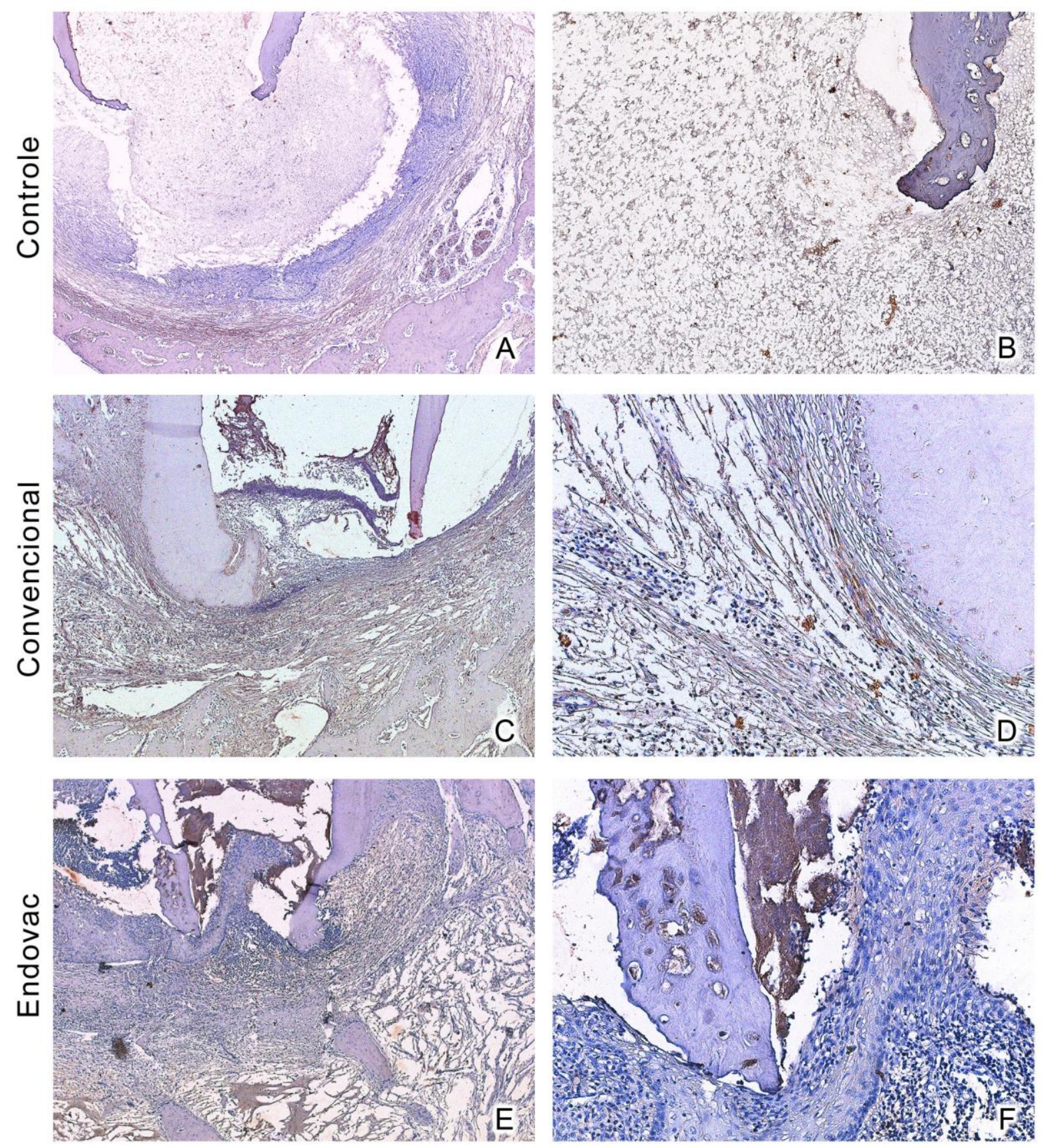

Após análise das imunomarcações para ALP (Figura 6), observou-se diferença estatisticamente significante entre os grupos $(p=0,0021)$, sendo que 0 grupo Endovac ${ }^{\circledR}$ apresentou marcação significantemente mais intensa com relação ao grupo controle. Em porcentagem e considerando a classificação da marcação para ALP como ausente (escore 0 ), suave (escore 1 ), moderada (escore 2 ) e intensa (escore 3), foram obtidos os seguintes resultados, respectivamente: $75 \%, 12,5 \%$, $12,5 \%$ e $0 \%$ para o grupo controle; $0 \%, 85,7 \%, 14,3 \%$ e $0 \%$ para a irrigação convencional; e $0 \%, 14,3 \%, 85,7 \%$ e $0 \%$ para o grupo tratado com o Endovac ${ }^{\circledR}$.

Ressalta-se que a marcação para ALP concentrava-se na região do osso ao redor da lesão, como pode ser observado nas imagens da Figura 7.

Figura 6. Escores obtidos após a avaliação das imunomarcações para ALP e comparação entre os grupos. Escore $0=$ ausente; $1=$ imunomarcação suave; $2=$ moderada; $3=$ intensa. Letras diferentes indicam diferença estatisticamente significante $(p=0,0021)$

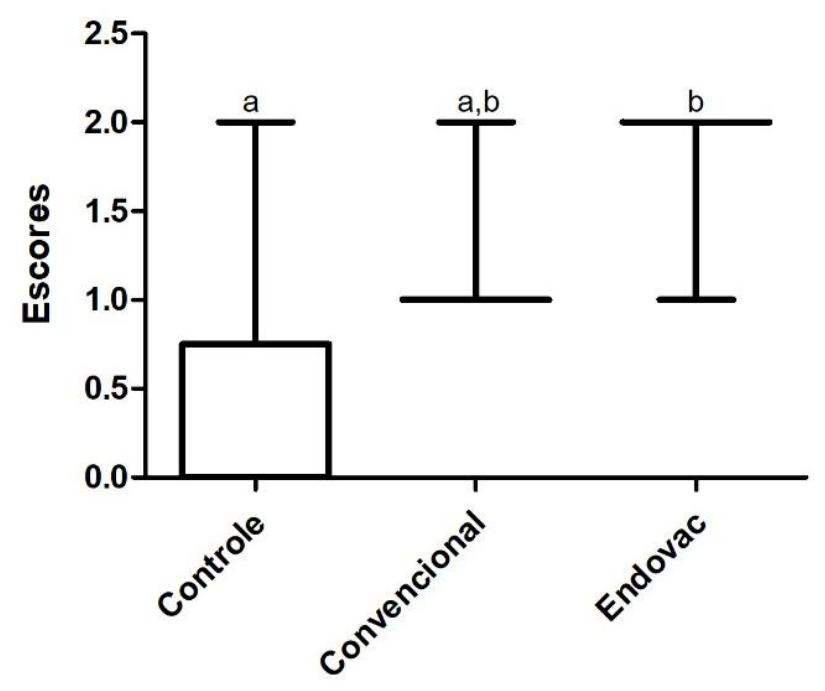


Figura 7. Fotomicrografias representativas da intensidade de imunomarcação para a Fosfatase Alcalina (ALP) nos diferentes grupos. (A) Visão panorâmica do espécime do grupo Controle evidenciando ausência de marcação para ALP, como evidenciando em (B). (C) Visão panorâmica do espécime do grupo Convencional demonstrando marcação suave para ALP. (D) Detalhe da imagem anterior, evidenciando marcação suave de ALP concentrada na região próxima ao osso alveolar. (E) Visão panorâmica do espécime do grupo Endovac demonstrando marcação moderada de ALP, concentrada na região do osso alveolar ao redor da lesão periapical, como evidencia em maior aumento na Figura (F). Figuras A, C e E = aumento de 50X; Figuras B, D e F = aumento de 200X. 

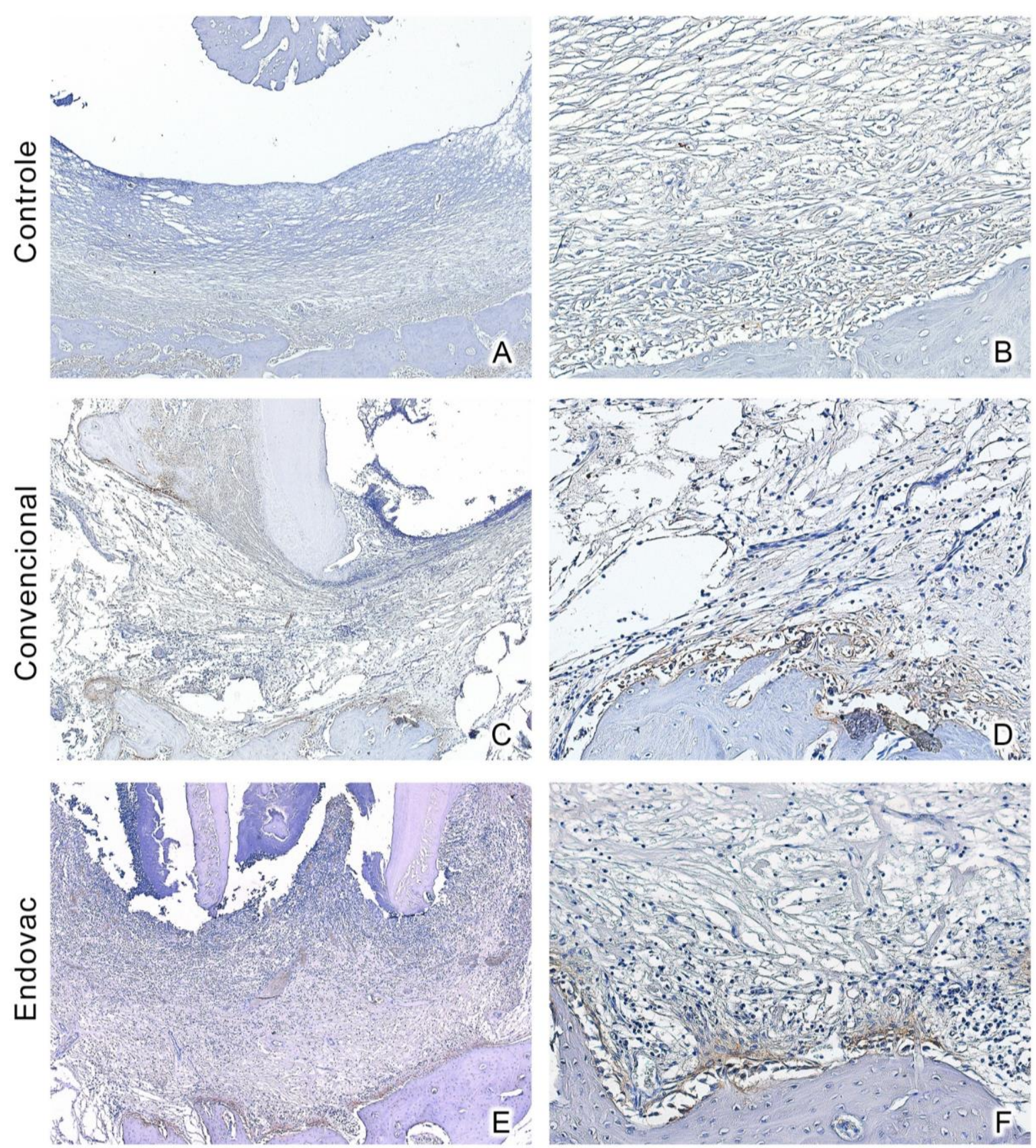

5. Discussão 



\section{DiscussÃo}

Tradicionalmente, o tratamento endodôntico de dentes permanentes com rizogênese incompleta com necrose pulpar consiste na estimulação do fechamento apical por meio de trocas de curativo de demora com pastas à base de hidróxido de cálcio (Rafter, 2005; da Silva et al., 2010; AAPD, 2016; Lin et al., 2017; Silva, 2018). No entanto, até se obter condições anatômicas que permitam a realização da obturação definitiva do canal radicular podem ser necessários vários meses. Além disso, esse protocolo de tratamento convencional pode comprometer a funcionalidade e o prognóstico a longo prazo do dente envolvido, uma vez que o mesmo apresentará a estrutura radicular intrinsecamente fragilizada e enfraquecida (Namour e Theys, 2014).

Assim, métodos alternativos têm sido propostos pela Associação Americana de Endodontia ( $A A E, 2016$ ), como a realização de procedimentos de revascularização, ampliando as possibilidades terapêuticas para dentes com necrose pulpar e ápice incompleto. Essas abordagens atuais permitem que as paredes do canal tornem-se mais resistentes e reforçadas e possibilitam a continuidade do desenvolvimento radicular (Bansal and Bansal, 2011; Hargreaves et al., 2013; Palma et al., 2017). A resposta ideal do tratamento seria o estímulo de formação de tecido conjuntivo pulpar no interior do canal (da Silva et al., 2010). No entanto, estudos têm demonstrado que o tecido formado após o procedimento de revascularização é de origem periodontal, apresentando natureza cementogênica, periodontal e óssea (Thibodeau et al., 2007; Becerra et al., 2014; Yang et al., 2016).

Os mecanismos envolvidos no reparo periodontal e na continuidade do desenvolvimento radicular em dentes permanentes com rizogênese incompleta e lesão periapical não estão completamente elucidados (Palma et al., 2017). De acordo com Palma et al. (2017), as estratégias para promover o crescimento de novos tecidos no interior do espaço pulpar baseiam-se em 4 conceitos fundamentais: 1Eliminação efetiva da infecção endodôntica; 2 - Recrutamento de células mesenquimais indiferenciadas da região apical; 3 - Criação de um arcabouço que permita o crescimento de um novo tecido e; 4 - Adequado selamento coronário para prevenir a re-infecção. 
Os resultados da terapia endodôntica regenerativa (RET) para o tratamento de dentes permanentes jovens, com ápice aberto, e presença de necrose pulpar e lesão periapical foram avaliados por Lin et al. (2017), em comparação à apicificação. Neste recente estudo clínico randomizado, parâmetros quantitativos obtidos em imagens de tomografia computadorizada de feixe cônico demonstraram que esta nova modalidade de tratamento ocasiona alterações morfológicas significativas na região apical, determinando aumento do comprimento radicular e da espessura das paredes, em comparação ao tratamento convencional. Ressalta-se que os objetivos primários de eliminação dos sintomas e de reparo ósseo, com desaparecimento da radiolusência apical, foram obtidos pelas duas modalidades terapêuticas em $100 \%$ dos casos.

O presente estudo avaliou o processo de formação de tecido mineralizado em nível apical após o emprego do sistema de irrigação por pressão negativa durante o tratamento endodôntico de dentes permanentes com rizogênese incompleta e lesão periapical. O preparo químico-mecânico tem como principal objetivo eliminar a infecção do sistema de canais radiculares, sendo uma etapa fundamental do tratamento endodôntico. No entanto, durante o uso de instrumentos endodônticos e da solução irrigadora, restos orgânicos e inorgânicos, bactérias e irrigantes podem ser extravazados, exacerbando a condição patológia periapical (Bürklein et al., 2013; Jamleh et al., 2016; Barbosa-Ribeiro et al.,2018). Sabe-se que quanto maior o diâmetro apical dos dentes, maior o risco de ocorrência de danos aos tecidos periapicais (Mehara et al., 2000; Gernhardt et al., 2004; Aksel et al., 2014). Conforme demostrado na literatura, o Endovac reduz consideravelmente a extrusão inadvertida de debris e de solução irrigadora (Azim et al., 2018; Venumbaka et al., 2018), enfatizando, assim, os efeitos biologicamente benéficos do seu emprego em dentes com rizogênese incompleta. Como vantagem adicional, verifica-se ainda uma melhor remoção de smear layer e de material necrótico do terço apical do canal, considerada a região mais intensamente contaminada, principalmente na presença de lesão periapical (Nielsen e Baumgartner, 2007; Shin et al., 2010; Abarajithan et al., 2011; Gade et al., 2013; Alkahtani et al., 2014; Dua e Dua, 2015; Versiani et al., 2016; Karade et al., 2017; Suman et al., 2017). 
Concordando com estudos prévios (da Silva et al., 2010; Versiani et al., 2016; Pucinelli et al.,2017), esse sistema promove uma adequada limpeza e desinfecção do sistema de canais radiculares e cria condições propícias à ocorrência do processo de reparo. Esses achados baseiam-se no fato de que os mecanismos celulares, moleculares e bioquímicos envolvidos na reparação tecidual são estimulados a partir da criação de um microambiente favorável. Eventos como migração, proliferação e diferenciação celular, bem como deposição e maturação de matriz, essenciais para a formação de tecido conjuntivo, ocorrem apenas diante do controle do processo infeccioso.

A indução de sangramento por meio de sobre - instrumentação na região apical tem sido a etapa realizada durante o procedimento de revascularização para formar um coágulo sanguíneo, produzindo um arcabouço no interior do canal (Banchs e Trope, 2004; Lin et al., 2017; Lucisano et al., 2016; Palma et al., 2017) e constituindo uma fonte de células viáveis, as quais são derivadas da circulação local, do cemento, ligamento periodontal ou osso alveolar (Ostby, 1961).

Além de atender o primeiro conceito de eliminação da infecção endodôntica, - Endovac também cumpre as funções de recrutamento de células mesenquimais indiferenciadas da região apical e de criação de um arcabouço, fundamentais para a indução de neoformação tecidual. A cinética da solução irrigadora no interior do canal, garantindo volume e limpeza até o comprimento real de trabalho, permite que a ampla abertura apical seja preenchida por coágulo sanguíneo, com a vantagem ainda de não ocasionar agressão os tecidos periapicais.

Diante do exposto, temos a seguinte situação proporcionada pelo emprego da irrigação por pressão negativa: contaminação microbiana controlada e consequente controle da resposta imunoinflamatória, indução do processo de reparo e estímulo de neoformação tecidual no interior do canal radicular. Esse tecido formado tem exibido estágios variados de mineralização, invaginando-se no interior do canal e proporcionando um selamento biológico apical (da Silva et al., 2010; Pucinelli et al., 2017).

Assim, justifica-se a relevância do presente estudo em se avaliar os mecanismos envolvidos no processo de mineralização após o emprego do Endovac. A expressão significativamente mais intensa dos marcadores RUNX2 e ALP, em 
comparação à irrigação por pressão positiva, revela o potencial mineralizador desse sistema. O RUNX2 tem sido relacionado à mineralização óssea e dentária e desempenha papel crucial na diferenciação de osteoblastos e na homeostase de tecidos mineralizados (Gaikwad et al., 2001; Fisher e Franz-Odendaal, 2012). Já a ALP atua no estágio inicial da mineralização, sendo expressa nas primeiras etapas da diferenciação de osteoblastos e odontoblastos e fornece o fosfato inorgânico para formar a hidroxiapatita (Schouten et al., 2009). Seu papel no reparo periapical pode ser confirmado pelos nossos resultados que demonstraram a expressão dessa proteína concentrada próximo do osso alveolar adjacente à lesão.

Diante da expressão mais intensa do RUNX2 e da ALP e considerando o papel indutor da diferenciação osteoblástica desses dois marcadores, uma correlação pode ser realizada com o estudo de Pucinelli et al. (2017), no qual foi observado um número significantemente menor de osteoclastos nos espécimes tratados pelo Endovac. Paralelamente, esses resultados sugerem uma reparação tecidual em estágio mais avançado após o emprego do sistema por irrigação negativa, estando de acordo com achados prévios (da Silva et al., 2010; Pucinelli et al., 2017).

Embora, sem diferença estatística com os demais grupos, a expressão de OPN nos espécimes submetidos à irrigação por pressão negativa corrobora e confirma o seu potencial reparador. Essa glicoproteína da matriz extracelular participa da manutenção ou reconfiguração da integridade tecidual durante os processos inflamatórios (Denhardt et al., 2001), confirmando a importância de sua expressão nos tecidos.

Além da formação de um arcabouço rico em células mesenquimais indiferenciadas, a presença de moléculas sinalizadoras são elementos essenciais para a geração de um tecido funcional (Yang et al., 2016). A identificação da expressão dos marcadores RUNX2, ALP e OPN no grupo tratado pelo sistema de irrigação por pressão negativa demonstra relevância biológica, confirmando o potencial reparador e mineralizador desse sistema. 
6. Conclusão 



\section{CONCLUSÃo}

Com base nas condições metodológicas e nos resultados do presente estudo, é possível concluir que a irrigação por pressão negativa induz a expressão de marcadores com fenótipo mineralizador na região apical de dentes com rizogênese incompleta e lesão periapical, sendo considerado o método de irrigação mais adequado. 

Referências 



\section{REFERÊNCIAS}

Abarajithan M, Dham $S$, Velmurugan N, vValerian-Albuquerque $D$, Ballal $S$, Senthilkumar $\mathrm{H}$. Comparison of Endovac irrigation system with conventional irrigation for removal of intracanal smear layer: an in vitro study. Oral Surg Oral Med Oral Pathol Oral Radiol Endod. 2011 Sep;112(3):407-11.

Adorno CG, Fretes VR, Ortiz CP, Mereles R, Sosa V, Yubero MF, Escobar PM, Heilborn C. Comparison of two negative pressure systems and syringe irrigation for root canal irrigation: an ex vivo study. Int Endod J. 2015 Jan 29.

Alkahtani A, Al Khudhairi TD, Anil S. A comparative study of the debridement efficacy and apical extrusion of dynamic and passive root canal irrigation systems. BMC Oral Health. 2014 Feb 11;14:12.

Aksel H, Askerbeyli S, Canbazoglu C, Serper A. Effect of needle insertion depth and apical diameter on irrigant extrusion in simulated immature permanent teeth. Braz Oral Res. 2014;28:1-6.

American Association of Endodontists. Guide to Clinical Endodontics. Sixth Edition. 2016;1-40.

Azim AA, Aksel H, Margaret Jefferson M, Huang GT. Comparison of sodium hypochlorite extrusion by five irrigation systems using an artificial root socket model and a quantitative chemical method. Clin Oral Investig. 2018

Mar;22(2):1055-1061.

Bansal R, Bansal R. Regenerative endodontics: a state of the art. Indian J Dent Res. 2011 Jan-Feb;22(1):122-31.

Barbosa-Ribeiro M, Arruda-Vasconcelos R, Fabretti FL, Silva EJNL, De-Deus G, Gomes BPFA. Evaluation of Apically Extruded Debris Using Positive and Negative Pressure Irrigation Systems in Association with Different Irrigants. Braz Dent J. 2018 MarApr;29(2):184-188.

Banchs F, Trope M. Revascularization of immature permanent teeth with apical periodontitis: new treatment protocol? J Endod. 2004 Apr;30(4):196-200.

Becerra P, Ricucci D, Loghin S, Gibbs JL, Lin LM. Histologic study of a human immature permanent premolar with chronic apical abscess after revascularization/revitalization. J Endod. 2014 Jan;40(1):133-9.

Byström A, Sundqvist G. Bacteriologic evaluation of the efficacy of mechanical root canal instrumentation in endodontic therapy. Scand J Dent Res. 1981 Aug;89(4):3218.

Buldur B, Kapdan A. Comparison of the EndoVac system and conventional needle irrigation on removal of the smear layer in primary molar root canals. Niger J Clin Pract. 2017 Sep;20(9):1168-1174. 
Bürklein S, Benten S, Schafer E. Quantitative evaluation of apically extruded debris with different single-file systems: Reciproc, F360 and OneShape versus Mtwo. Int Endod J 2013;47:405-409.

Cohenca N, Heilborn C, Johnson JD, Flores DS, Ito IY, da Silva LA. Apical negative pressure irrigation versus conventional irrigation plus triantibiotic intracanal dressing on root canal disinfection in dog teeth. Oral Surg Oral Med Oral Pathol Oral Radiol Endod. 2010;109(1):e42-6.

Cohenca N, Silva LA, Silva RA, Nelson Filho, Heilborn C, Watanabe E, Saraiva MC Avaliação microbiológica de diferentes protocolos de irrigação no canal radicular desinfecção em dentes com periodontite apical: estudo in vivo. Braz Dent J. 2013 de setembro a outubro; 24 (5): 467-73.

Cohenca N, Romualdo PC, da Silva LA, da Silva RA, de Queiroz AM, De Rossi A, Nelson-Filho $P$. Tissue response to root canal irrigation systems in dogs' teeth with apical periodontitis. Clin Oral Investig. 2015 zun;19(5):1147-56.

da Silva LA, Nelson-Filho P, da Silva RA, Flores DS, Heilborn C, Johnson JD, Cohenca $\mathrm{N}$. Revascularization and periapical repair after endodontic treatment using apical negative pressure irrigation versus conventional irrigation plus triantibiotic intracanal dressing in dogs' teeth with apical periodontitis. Oral Surg Oral Med Oral Pathol Oral Radiol Endod. 2010;109(5):779-87.

Desai P, Himel V. Comparative safety of various intracanal irrigation systems. J Endod 2009; 35: 545-9. 2.

Denhardt DT, Noda M., O'Regan AW, Pavlin D, Berman JS. Osteopontin como um meio para lidar com insultos ambientais: regulação da inflamação, tecido remodelação e sobrevivência celular. J Clin Invest. Maio de 2001; 107 (9): 1055-61.

de Miranda RG, Gusman HD, Colombo AP. Antimicrobial efficacy of the EndoVac system plus PDT against intracanal Candida albicans: an ex vivo study. Braz Oral Res. 2015;29(1):S1806-83242015000100308.

Druttman ACS, Stock CRJ. An in vitro comparison of ultrasonic and convencional methods of irrigant replacement. Int Endod J.1989;22:174-8.

Dutner J, Mines P, Anderson A. Irrigation trends among American Association of Endodontists members: a web-based survey. J Endod. 2012;38(1):37-40.

Dua A, Dua D. Comparative evaluation of efficacy of EndoVac irrigation system to Max-I probe in removing smear layer in apical $1 \mathrm{~mm}$ and $3 \mathrm{~mm}$ of root canal: An in vitro scanning electron microscope study. Dent Res J (Isfahan). 2015 JanFeb;12(1):38-43

Fisher S, Franz-Odendaal T. Evolution of the bone gene regulatory network. Curr Opin Genet Dev. 2012 Aug;22(4):390-7. doi: 10.1016/j.gde.2012.04.007. Epub 2012 Jun 2. 
Fukumoto Y, Kikuchi I, Yoshioka T, Kobayashi C, Suda H. An ex vivo evaluation of a new root canal irrigation technique with intracanal aspiration. Int Endod J.2006 Feb;39(2):93-9.

Gade VJ, Sedani SK, Lokade JS, Belsare LD, Gade JR. Comparative evaluation of debris removal from root canal wall by using EndoVac and conventional needle irrigation: An in vitro study. Contemp Clin Dent. 2013 Oct;4(4):432-6.

Gaikwad JS, Cavender A, D'Souza RN. Identification of tooth-specific ownstream targets of Runx2. Gene. 2001 Nov 14;279(1):91-7.

Gernhardt CR, Eppendorf K, Kozlowski A, Brandt M. Toxicity of concentrated sodiumhypochlorite used as an endodontic irrigant. Int Endod J. 2004;37(4):272-80.

Gondim E Jr, Setzer FC, Dos Carmo CB, Kim S. Postoperative pain after the application of two different irrigation devices in a prospective randomized clinical trial. J Endod. 2010;36(8):1295-301.

Hargreaves KM, Diogenes A, Teixeira FB. Treatment options: biological basis of regenerative endodontic procedures. Pediatr Dent. 2013 Mar Apr;35(2):129-40.

Hülsmann M, Hahn W. Complications during root canal irrigation - literature review and case reports. Int Endod J. 2000 May;33(3):186-93. Review.

Hockett JL, Dommisch JK, Johnson JD, Cohenca N. Antimicrobial efficacy of two irrigation techniques in tapered and nontapered canal preparations: an in vitro study. J Endod. 2008 Nov;34(11):1374-7.

Jamleh A, Fukumoto Y, Takatomo Y, Kobayashi C, Suda H, Adorno CG. A comparison between two negative pressure irrigation techniques in simulated immature tooth: an ex vivo study. Clin Oral Investig. 2016;20(1):125-31.

Kakehashi S, Stanley HR, Fitzgerald RJ. The effects of surgical exposures of dental pulps in germ-free and conventional laboratory rats. Oral Surg Oral Med Oral Pathol $1965 ; 20: 340-349$.

Kara Tuncer A, Unal B. Comparison of sealer penetration using the EndoVac irrigation system and conventional needle root canal irrigation. J Endod. 2014 May;40(5):613-7.

Karade P, Chopade R, Patil S, Hoshing U, Rao M, Rane N, Chopade A, Kulkarni A. Eficiência de Diferentes Sistemas Endodônticos de Irrigação e Ativação na Remoção da Camada de Smear: Um Estudo de Microscopia Eletrônica de Varredura. Iran Endod J. 2017 Fall; 12 (4): 414-418.

Leonardo MR, Silva LA, Leonardo RT, Utrilla LS, Assed S. Histological evaluation of therapy using a calcium hydroxide dressing for teeth with incompletely formed apices and periapical lesions. J Endod. 1993;19:348-52. 
Lin J, Zeng Q, Wei X, Zhao W, Cui M, Gu J, Lu J, Yang M, Ling J. Regenerative Endodontics Versus Apexification in Immature Permanent Teeth with Apical Periodontitis: A Prospective Randomized Controlled Study. J Endod. 2017 Nov;43(11):1821-1827.

Lucisano MP, Nelson-Filho P, Silva LA, Silva RA, de Carvalho FK, de Queiroz AM. Apical Revascularization after Delayed Tooth Replantation: An Unusual Case. Case Rep Dent. 2016;2016:2651643. Epub 2016 Nov 2.

Mancini M, Cerroni L, Iorio L, Dall'Asta L, Cianconi L. FESEM evaluation of smear layer removal using different irrigant activation methods (EndoActivator, EndoVac, PUI and LAI). An in vitro study. Clin Oral Investig. 2018 Mar;22(2):993-999.

Machado R, Cruz ATG, de Araujo BMM, Klemz AA, Klug HP, da Silva Neto UX. Tubular dentin sealer penetration after different final irrigation protocols: A confocal laser scanning microscopy study. Microsc Res Tech. 2018 Jun;81(6):649-654.

Mehara P, Clancy C, Wu J. Formation of facial hematoma during endodontic therpy. J Am Dent Assoc. 2000 Jan;131(1):67-71.

Mitchell RP, Yang SE, Baumgartner JC. Comparison of apical extrusion of $\mathrm{NaOCl}$ using the EndoVac or needle irrigation of root canals. J Endod. 2010;36(2):338-41.

Namour M, Theys S. Pulp revascularization of immature permanent teeth: a reviewof the literature and a proposal of a new clinical protocol. ScientificWorldJournal. 2014; 2014: 737503.

Nielsen BA, Baumgartner J. Comparison of the EndoVac system to needle irrigation of root canals. J Endod 2007;33:611-5.

Ostby BN. The role of the blood clot in endodontic therapy. An experimental histologic study. Acta Odontol Scand. 1961 Dec;19:324-53.

Palma PJ, Ramos JC, Martins JB, Diogenes A, Figueiredo MH, Ferreira P, Viegas C, Santos JM. Histologic Evaluation of Regenerative Endodontic Procedures with the Use of Chitosan Scaffolds in Immature Dog Teeth with Apical Periodontitis. J Endod. 2017 Aug;43(8):1279-1287.

Peters OA, Schönenberger K, Laib A. Effects of four Ni-Ti preparation techniques on root canal geometry assessed by micro computed tomography. Int Endod J. 2001;34(3):221-30.

Pucinelli CM, Silva LABD, Cohenca N, Romualdo PC, Silva RABD, Consolaro A, Queiroz AM, Nelson P Filho. Apical Negative Pressure irrigation presents tissue compatibility in immature teeth. J Appl Oral Sci. 2017 Nov-Dec;25(6):612-619.

Rafter M. Apexification: a review. Dent Traumatol. 2005 Feb;21(1):1-8. Review. 
Rocha CT, Rossi MA, Leonardo MR, Rocha LB, Nelson-Filho P, Silva LA. Biofilm on the apical region of roots in primary teeth with vital and necrotic pulps with or without radiographically evident apical pathosis. Int Endod J. 2008 Aug;41(8):664-9.

Rodríguez-Benítez S, Stambolsky Guelfand C, Martín-Jiménez M, Segura-Egea J]. Root canal disinfection of immature dog teeth with apical periodontitis: Comparison of three different protocols. J Clin Exp Dent. 2014;6(4):e357-63.

Romualdo PC, de Oliveira KM, Nemezio MA, Küchler EC, Silva RA, Nelson-Filho P, Silva LA. Does apical negative pressure prevent the apical extrusion of debris and irrigant compared with conventional irrigation? A systematic review and metaanalysis. Aust Endod J. 2017 Feb 2. doi: 10.1111/aej.12162)

Saber Sel-D, Hashem AA. Efficacy of different final irrigation activation techniques on smear layer removal. J Endod. 2011 Sep;37(9):1272-5.

Silva LAB. Pulpotomia em dentes descíduos e permanentes jovens. In: Odontopediatria: Bases científicas para a prática clínica. São Paulo: Ed. Artes médicas; 2005. p. 571-611.

Silva LAB. Tratamiento endodontico de dientes permanentes con rizogénesis incomplete. In: Tratado de Odontopediatría. Segunda Edición. Ed. Amolca; 2018.

Shin SJ, Kim HK, Jung IY, Lee CY, Lee SJ, Kim E. Comparison of the cleaning efficacy of a new apical negative pressure irrigating system with conventional irrigation needles in the root canals. Oral Surg Oral Med Oral Pathol Oral Radiol Endod. 2010 Mar;109(3):479-84.

Schouten C, van den Beucken JJ, de Jonge LT, Bronkhorst EM, Meijer GJ, Spauwen $\mathrm{PH}$, Jansen JA. The effect of alkaline phosphatase coated onto titanium alloys on bone responses in rats. Biomaterials. 2009 Nov;30(32):6407-17.

Schilder H. Cleaning and shaping the root canal. Dent Clin North Am 1974; 18:269296.

Sjøgren U, Figdor D, Persson S, Sundqvist G. Influence of infection at the time of root filling on the outcome of endodontic treatment of teeth with apical periodontitis. Int Endod J 1997;30:297-306.

Suman S, Verma P, Prakash-Tikku A, Bains R, Kumar-Shakya V. A Comparative Evaluation of Smear Layer Removal Using Apical Negative Pressure (EndoVac), Sonic Irrigation (EndoActivator) and Er:YAG laser -An In vitro SEM Study. J Clin Exp Dent. 2017 Aug 1;9(8):e981-e987. doi: 10.4317/jced.53881. eCollection 2017 Aug.

Tanomaru-Filho M, Miano LM, Chávez-Andrade GM, Torres FF, Leonardo Rde T, Guerreiro-Tanomaru JM. Cleaning of Root Canal System by Different Irrigation Methods. J Contemp Dent Pract. 2015;16(11):859-63. 
Thibodeau B, Trope M. Revascularization of the pulp of a necrotic infected immature permanent tooth: case report and literature review. Pediatr Dent. 2007 Jan - fev; 29 (1): 47-50.

Vaudt J, Bitter K, Neumann K, Kielbassa AM. Ex vivo study on root canal instrumentation of two rotary nickel-titanium systems in comparison to stainless steel hand instruments. Int Endod J. 2009;42:22-33.

Velmurugan N, Sooriaprakas C, Jain P. Apical Extrusion of Irrigants in Immature Permanent Teeth by Using EndoVac and Needle Irrigation: An In Vitro Study. J Dent (Tehran). 2014;11(4):433-9.

Venumbaka NR, Baskaran P, Mungara J, Chenchugopal M, Elangovan A, Vijayakumar

P. Comparative Evaluation of Endovac and Conventional Irrigating Syringe on Apical Extrusion in Primary Molars. An in vitro Study. J Clin Pediatr Dent. 2018 May 15.

Vera J, Siqueira JF Jr, Ricucci D, Loghin S, Fernández N, Flores B, Cruz AG. Oneversus two-visit endodontic treatment of teeth with apical periodontitis: a histobacteriologic study. J Endod. 2012 Aug;38(8):1040-52.

Versiani MA, Alves FR, Andrade-Junior CV, Marceliano-Alves MF, Provenzano JC, Rôças IN, Sousa-Neto MD, Siqueira JF Jr. Micro-CT evaluation of the efficacy of hardtissue removal from the root canal and isthmus area by positive and negative pressure irrigation systems. Int Endod J. 2016;49(11):1079-1087.

Wang J, Jiang Y, Chen W, Zhu C, Liang J. Bacterial flora and extraradicular biofilm associated with the apical segment of teeth with post-treatment apical periodontitis. J Endod. 2012 Jul;38(7):954-9.

Willershausen I, Wolf TG, Schmidtmann I, Berger C, Ehlers V, Willershausen B, Briseño B. Survey of root canal irrigating solutions used in dental practices within Germany. Int Endod J. 2015;48(7):654-60.

Yang J, Yuan G, Chen Z. Regeneração de Celulose: Abordagens Atuais e Futuro Desafios Front Physiol. 20167 de março, 7: 58.

Zeng C, Meghil MM, Miller M, Gou Y, Cutler CW, Bergeron BE, Niu L, Ma J, Tay FR. Antimicrobial efficacy of an apical negative pressure root canal irrigation system against intracanal microorganisms. J Dent. 2018 May;72:71-75.

Zhu WC, Gyamfi J, Niu LN, Schoeffel GJ, Liu SY, Santarcangelo F, Khan S, Tay KC, Pashley DH, Tay FR. Anatomy of sodium hypochlorite accidents involving facial ecchymosis - a review. J Dent. 2013;41(11):935-48. 
Anexo 

Anexo A - Certificado de aprovação do trabalho no Comitê de Ética no Uso de Animais

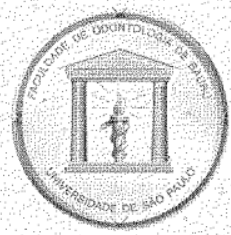

\section{Universidade de São Paulo Faculdade de Odontologia de Bauru}

Comissão, de Ética no Ensino e Pesquisa em Animais

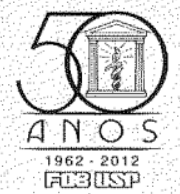

CEEPA-PROC. $N 0006 / 2012$

Bauru, 27 de março de 2012.

Senhor Professor

O projeto de pesquisa encaminhado a esta Comissão de Ética no Ensino e Pesquisa em Animais, denominado Irrigação por pressão negativa (EndoVac) versus irrigação convencional - Estudo histopatológico, imunohistoquímico e histoenzimológico em dentes de cães com lesão periapical, de autoria de Priscilla Coutinho Romualdo, sob sua orientação foi enviado ao relator para avaliação e considerado APROVADO em reunião desta Comissão realizada no dia 26 de março de 2012.

Solicitamos que ao final da pesquisa seja enviado, para avaliação desta Comissão, um Relatório com os resultados obtidos para análise ética e emissão de parecer final, o qual poderá ser utilizado para fins de publicação científica.

Atenciosamente,

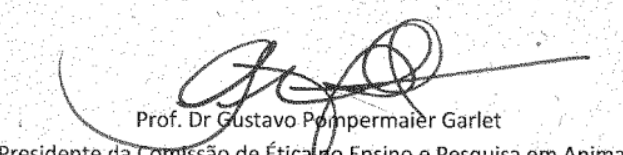

Presidente da Comissão de Éticaldo Ensino e Pesquisa em Animais

Prof. Dr. Paulo Nelson Filho

Docente do Departamento de Clínica Infantil, Odontologia Preventiva e Socia

Faculdade de Odontologia de Ribeirão Preto - USP

AI. Dr. Octávio Pinheiro Brisolla, 9-75 - Bauru-SP - CEP 17012-101 - C.P. 73 e-mail: mferrari@fob.usp.br - Fone/FAX (0xx14) 3235-8356

http.//www.fob usp.br 